\title{
The Leadership Skills That Influence Performance in an Organizational Context
}

\author{
Konstantinos Nikolaou, M Sc. ${ }^{1}$ and Dr. Evangelia Markaki ${ }^{2}{ }^{*}$ \\ ${ }^{1}$ Master's degree graduate in Business Administration, Mediterranean College, Athens, Greece \\ ${ }^{2}$ Business School Professor, Mediterranean College, Athens, Greece \\ *Corresponding author
}

\begin{abstract}
The following study is an exploratory research regarding the leadership characteristics that may work as prerequisites for a high job performance. The study was conducted as a dissertation for the completion of the Master's studies program in Business Administration on a global context, as offered by Mediterranean College in partnership with University of Derby. The aim of the study was to further research, which are the leadership characteristics that work as prerequisites for a high job performance and it was approached through relevant literature review and an electronic quantitative survey. The findings were used for a proposal of contemporary solutions regarding the effectiveness of modern leadership characteristics in changing the inner cultures of businesses and organizations, in order to keep them up resilient in harsh periods.
\end{abstract}

Keywords: Leadership; Performance; Resilience; Change management

\section{Introduction}

In nowadays strikingly different times, due to the covid - 19 pandemic, the exploration of the main force behind the survival of humanity may be a path to be followed for a resilient future, yet being a challenging one. The overall situation faced worldwide at the moment is relatively something unknown, albeit specific thoroughly developed and executed solutions have helped towards the sustainability of the key activities of a modern lifestyle. But without a vision and without a sound attitude towards constant improvement and development the crisis shall not be over. And the prominent force, widely considered for a long time, making all these facts happen is one, leadership.

Leadership may be concisely defined as "a process of social influence in which a person can enlist the aid and support of others in the accomplishment of a common task" (Chemers, 1997). As a social action, it is deeply bonded with the development of societies worldwide while ample diverse characteristics have been widely analyzed and observed on those who apply leadership, the leaders. Henry Miller defines "the real leader" as one who "has no need to lead - he is content to point the way", and this contentedness is what through this study the writer intends to research. The aim of this study is to further research, which are the leadership characteristics that work as prerequisites for a high job performance and four specific objectives shall be set towards the exploration of it. The primary objective is to (1) thoroughly research the modern theoretical background existing regarding leadership theories and job performance attributes, 
while an (2) analysis and research specifically on transformational leadership towards job performance is the second one. As a combined result of these two objectives, a (3) research based on modern leadership and job performance views, such as empathy, mindfulness, selflessness and compassion, and (4) the proposal of possible solutions regarding the introduction of a resilience and change culture interconnected with leadership and job performance, are the third and the fourth objective respectively.

\section{Literature Review}

As the aim of this study is to elicit and research, which are the leadership characteristics that may work as prerequisites for a high job performance, the analysis of substantial relevant literature shall be a mean to shed light on the existing knowledge and open a path for further recommendations. The following resources briefly analyzed are divided in three chapters in accordance to their topic, a theoretical overview of leadership and job performance, transformational leadership and other approaches that may be useful for even greater changes, as means to be used building - up a culture towards resilience.

Since the rise of the behavioral theories started, several more modern approaches on leadership in a "new humanism" approach appeared. Chester Barnard (Barnard, 1948) thought that organization is a system of coordination of human actions. The employees, he suggests, accept consciously to obey orders, if and when they understand the goals and operation of the organization ("acceptance theory"). Besides the typical organization, there is an informal one formed through human relationships and contacts he also mentions. Elton Mayo (Mayo, 2004) thought that emotional factors were more important than the physical and logical factors while Mary Parker Follett (Follett, 1918) believed that managers should recognize that each employee emotional and psychological world is complex. Also instead of dictating commands, managers should give appropriate incentives she comments.

Kurt Lewin with Lippitt and White on a more analytic approach for their time, identified three key models of leadership behavior, as an effort of better understanding towards leadership styles, the authoritarian, the democratic and the laissez faire (Lewin et al., 1939).Daniel Goleman also presents a widely acknowledged contemporary approach towards leadership styles (Goleman, 2000). Six different styles exist according to the writer, the commanding, the visionary, the affiliative, the democratic, the pacesetting and the coaching, each one connected with a different modus operandi, that may be concisely described in a single phrase

As ground - breaking changes have been taking place worldwide during the first term of 2020 due to the covid - 19 pandemic, transformational leadership may be an apparent part of nowadays leaders' attitude. The organizations' resilience and operational capability are deeply challenged, thus concise solutions of leadership through a change shall be a solution. Heifetz and Laurie propose a contemporary approach, which shall be fit in today's reality, in their article "The work of leadership (Heifetz and Laurie, 2002). Daniel Goleman suggests that a great leader is a smoothly balanced personality equipped adequately with self - awareness, self - regulation, motivation, empathy and social skills (Goleman, 1998) while Rooke and Torbert, divide leaders in seven types of action logic, Opportunist, Diplomat, Expert, Achiever, Individualist, Strategist and Alchemist (Rooke and Torbert, 2005). Today's business environments, according to the writers', are in need for a transition of Experts to Achievers, Achievers to Individualists and Individualists to Strategists. Alchemists are very 
rare, while Opportunists are less favored and Diplomats are mostly preferred unchanged. Depending on the person, a transition from the one leadership action logic to another is possible if, more or less, the five characteristics mentioned by Goleman are evolved.

A rather promising and contemporary strategy is proposed by Hougaard and Carter in their book "The Mind of The Leader" (Hougaard and Carter, 2018), proposing a fundamental and dynamic scheme to be applied by any business leader, briefly mentioned as $\mathbf{M}-\mathbf{S}-\mathbf{C}$ Leadership ( $\mathbf{M}$ for Mindfulness, $\mathbf{S}$ for Selflessness and $\mathbf{C}$ for $\mathbf{C o m p a s s i o n ) . ~ T h e s e ~ s p e c i f i c ~}$ traits are mentioned as a way that shall be the introduction of a different mindset across the high - end officials of an organization, firstly in themselves and secondly towards their employees in their departments. Mindfulness according to the writers, is based on a person's focus and awareness towards what he / she is facing, selflessness is achieved if balanced by a leader with confidence, and compassion is ensured as a process combining a caring yet wise leader's character who shall provide solutions to the employee's problems in order to help him/ her get back to work more efficiently. Empathy is evidently opposed against compassion, as the authors consider it as a "weeping culture" that makes the leader rather too sensitive and not helpful for the employees' problems as it ends up to an empathetic hijack and may not provide alleviating solutions (Hougaard and Carter, 2018)

\section{Methodology}

\subsection{Research Hypothesis}

As the three of the four objectives demanded way more than a simple literature review to be covered, subsequent generic research had to be followed. Following the analysis of the relevant literature, four research hypotheses were set for this generic research, as presented below. The validity of these hypotheses is discussed in the concluding sections of the study.

Hypothesis 1: Gender, age and monthly allowance affect the perception one has towards the leadership skills that influence high job performance: It has been acknowledged in similar researches so far that there are differences between different participants groups in a survey, based on demographic data

Hypothesis 2. General Leadership Skills that influence high job performance have in overall a high level of approval among the public. Especially Trustworthiness, Dependability, Friendliness, Outgoingness, Empathy and Articulateness have the highest levels of agreeability: As a matter of fact for the common logic, any potential leader is believed to be skilled with certain leadership characteristics. Certain of them are assumed as highly probable to be influencing high job performance, thus having wider acceptance among the public.

Hypothesis 3: Transformational Leadership skills also have a relatively high level of acceptance between the public regarding organizational leaders' abilities towards developing high job performance on their employees, while the implementation of these transformations leans solely to the leader: It is believed that transformations in businesses and organizations lean on the leaders themselves, but it shall be also important to research the role of the employees in these actions.

Hypothesis 4: Modern Leadership Theories have moderate to low level of acceptance among the public, although high job performance is addressed by them: Contemporary approaches striking mindfulness, selflessness, compassion, empathy in leadership are 
considered as unfit for a vast amount of both employers and employees, regardless their influence on high job performance

\subsection{Research philosophy}

In order to provide an analysis corresponding in the objectives of this study, the philosophy of positivism is followed. As the aim of this research is to further research, which are the leadership characteristics that work as prerequisites for a high job performance, the presentation of sound and clear data, as well as, the proposal of possible and effective recommendations shall be provided. In a positivist approach, the validity of the results, the diversity of the sample for data collection and also the privacy of the participants in the research are rather more ensured as it is proposed by Bryman and Bell (Bryman and Bell, 2009). It is also worth noting that although initially this study was appointed towards a realistic approach, with the use of means combining both the philosophies of positivism and interpretivism, as a more realistic approach. But as a rather more objective, yet efficient, approach positivism was the final choice. As Saunders et al. have also noted in their book, mixed data or sole phenomenological approaches of individuals may not provide objective analysis to the extent of anonymous quantitative data (Saunders et al., 2016).

\subsection{Research Design / Strategy}

A Quantitative survey amongst 100 participants was used for the completion of this study, with an exploratory attitude. As it is suggested in the objectives of the study the introduction of possible recommendations towards a culture of change and resilience, through the leadership characteristics that work as prerequisites for a high job performance is a demanding task. And with a strategy designed and adopted towards the collection of rather objective, anonymous stances, the aim of the study may be more adequately validated than with a more phenomenological approach. The survey was cross - sectional, with a questionnaire being available for three months between April and July 2020.

Descriptive statistics were used for the analysis of the results as, a descriptive research, such as that undertaken using attitude and opinion questionnaires and questionnaires of organizational practices, enables the identification and description of the variability in different phenomena. With the use of a survey for this study, the data collected can be used to suggest possible reasons for particular relationships between variables and to produce models of these relationships (Saunders et al., 2016). Attainable proposals for further development of a change and resilience culture may be also a result of the analysis of this survey

\subsection{Methods - Data Collection}

A mono - method quantitative approach was used in this study, as a data collection mean. A questionnaire of a total of 48 questions was used, with 45 likert scale questions rated from one to five and three multiple choice questions. Three questionnaires deriving from recognized academic resources were used in order to answer the second and the third of the four objectives of the study. The participants in this survey are mainly asked to rate the significance and relevance of statements and attitudes towards a person they consider a leader. Specifically, in the first section of the survey a questionnaire titled the "Leadership Trait Questionnaire" (LTQ) from Peter Northouse's book "Leadership" Theory and Practice" (Northouse, 1997) was used for data collection towards general leadership skills, therefore answering the first objective of the study, to thoroughly research the modern theoretical background existing regarding leadership theories and job performance attributes. This 
questionnaire consisted of fourteen (14) statements to be rated from one (1) to five (5) (Northouse, 1997). The participants are asked to rate from one to five the significance of the fourteen statements for a person they consider a leader. The second section of the survey contained a transformational leadership questionnaire combined with an $\mathrm{M}-\mathrm{S}-\mathrm{C}$ leadership questionnaire (M for Mindfulness, $\mathbf{S}$ for Selflessness and $\mathbf{C}$ for Compassion), deriving from the "Transformational Leadership Questionnaire" of D.D. Warrick (Warrick, 2011) and the book of Hogaard and Carter "The Mind of the Leader" (Hoogaard and Carter, 2018) as a method answering the third objective of the study, a research based on modern leadership and job performance views, such as empathy, mindfulness, selflessness and compassion. Especially for empathy, a separate section was conducted in the questionnaire, based on the "Toronto Empathy Questionnaire" (Spreng et al., 2009). All the questions used where adopted on a likert scale rated from one to five with a scoring key as following, $5=$ Strongly agree, $4=$ Agree, 3 = Neutral, 2 = Disagree, 1 = Strongly disagree. The likert - scale method is used as "a method simple to administer and therefore extremely popular is business researchers, as the respondents indicate their attitudes by checking how strongly they agree or disagree with the carefully constructed statements, ranging from very positive to very negative" (Zikmund et al., 2010 , pp. 318 -319). The lineup of the 48 questions, in their exact form, as they were available in Google Forms is presented below, with further explanations regarding the usability of each question / section

\section{Analysis - Results}

With all the relevant literature into consideration and with the use of a specifically conducted quantitative survey, an approach towards the aim of this study was performed. A research on which are the leadership characteristics that work as prerequisites for a high job performance has been made and the results presented below shall be a modest proposal of broader knowledge available on the topic.

\subsection{Demographic Data}

Gender, age and monthly allowance data were collected in the initial section of the survey, as presented in the charts bellow. Male participants were more than female, with $56 \%$ being male and $44 \%$ being female from a total of 100 participants.

The age of the participants was divided in three different categories, being $18-35,35-55$ and $55+$. Most of the participants in the survey were on the $18-35$ age section $(58,9 \%)$. The following most populous participant age section was the $35-55(32,2 \%)$ and $55+(8,9 \%)$ was the least populous participant team.

The monthly allowance of the participants was also a multiple - choice question available in the first section, with $32 \%$ of the participants having an income up to $800 €, 37 \%$ having an income between $800 €$ and $1500 €, 20 \%$ having an income between $1500 €$ and $2500 €$, and $11 \%$ having an income over $2500 €$.

In the three sections of the questionnaire that were rated in the Likert - scale from One (1) to Five (5), One (1) stood for "Strongly Disagree, Two (2) stood for "Disagree", Three (3) stood for "Neither Agree or Disagree", Four (4) stood for "Agree" and Five (5) stood for "Strongly Disagree". The

As in order to achieve the aim of this study, four specific objectives have been set, it would be unwise not to construct the analysis of the four separate sections of the survey conducted based on these objectives. Each separate part of the four likert - scale entities of the questionnaire 
derives from the four objectives of the study and the consolidated results of each section are presented bellow, followed by corresponding charts.

\subsection{Results of section 1: General Leadership Skills}

Fourteen (14) statements to be rated from one (1) to five (5) were available on this section. The questionnaire is based on Peter Northouse's "Leadership Trait Questionnaire" (Northouse, 1997). The Mean value from one (1) to five (5) on the likert scale for the fourteen (14) questions of this section is 4,25 for 100 answers in the survey, while the mean value from one (1) to five (5) for each question is Articulate 85\%, Perceptive 88,2\%, Self - confidence 89\%, Self assurance 83,8\%, Persistence 87\%, Determination 85,8\%, Trustworthiness 87,4\%, Dependability 83,8\%, Friendliness 79,6\%, Outgoingness 78,6\%, Conscientiousness 83,6\%, Diligence $86,6 \%$, Sensitivity 78,2\% and Empathy 79,6\%, as each question was a statement towards a leadership trait. The standard deviation of the mean values for each statement is 0,18 .

As it is depicted above, amongst the one hundred (100) participants of this survey, each and every leadership trait is considered of a high significance, while the variance between the ratings will be mentioned thoroughly in the following discussion section. It appears that each and every of the one hundred participants has an overall perception of a multilateral personality, when it comes to selecting the traits of a powerful leader, regardless his / her age, gender, monthly allowance.

\subsection{Results of Section 2: Transformational Leadership Skills}

In the second section of the Likert - scaled questions, a form of the "Transformational Leadership Questionnaire" of D.D. Warrik is applied (Warrik, 2011). Eight (8) statements rated from one (1) to five (5) are available, regarding the relevance of the leader each participant has in mind with the transformational skills mentioned. The mean value rating in overall from 1 to 5 for this section is 4,13 , while the for 100 answers in the survey, while the mean value from one (1) to five (5) for each separate statement is the following, Leading for a change:Vision $85,7 \%$, Direction $86,6 \%$, Inspiration $83,7 \%$ Championing Change: Initiating Change 82,0\%, Facilitating Change 79,8\%, Implementing Change 79,6\%, Transforming Organizations: Knowing Present Realities 84,9\%, Identifying Future Ideals 81,0\%, Developing And Implementing A Process For Transforming Organizations 79,1\%. The standard deviation of the mean values for each statement is 0,14 .

\subsection{Results of Section 3: M - S - C Leadership}

In the third section of the questionnaire, six (6) statements regarding $\mathbf{M}-\mathbf{S}-\mathbf{C}$ Leadership were available. $\mathbf{M}$ stands for Mindfulness, $\mathbf{S}$ stands for Selflessness and $\mathbf{C}$ stands for Compassion and this proposed leadership attitude derived from the book of Hougaard and Carter " The Mind of the Leader" (Hougaard and Carter, 2018). The six statements were again rated from one (1) to five (5) on the likert scale, with the overall mean value for the 100 participants being 4,19. The mean value rating in overall from 1 to 5 for this section is 4,13 , while the for 100 answers in the survey, while the mean value from one (1) to five (5) for each separate statement is, Focused on his duties $88,20 \%$, Aware of his duties 88,20\%, Selfless $77,60 \%$, Confident $88,20 \%$, Compassionate $80,60 \%$ and Wise $80,20 \%$. The standard deviation of the mean values for each statement is 0,25 .

The differences on the ratings of this section may be rather more interesting than in the previous parts of the questionnaire analysis. Selflessness, compassion and wisdom are clearly rated lower than the other proposed traits from the Mindfulness - Selflessness - 
Compassion leadership attitude. The first two rates, measure mindfulness, through the questioning of the leader's focus on his / her duties and awareness of his/ her duties (average 88,2\%). Selflessness is measured for a leader through the ratings of both selflessness and confidence (average $83 \%$ ), while compassion is measured through ratings for compassion and wisdom (average 80,4\%). The average ratings for each set of two measurements that was made for each of the three leadership traits in overall proposed in this template are presented in the chart bellow.

\subsection{Results of section 4: Empathy on Leadership}

In the fourth section of the questionnaire, six (6) statements regarding Empathy on Leadership were available. This proposed questionnaire derived from the "Toronto Empathy Questionnaire" (Spreng et al., 2009). The six statements were again rated from one (1) to five (5) on the likert scale, with the overall mean value for the 100 participants being 3,99. The results of this section were for each section, "Be upset to see someone being treated disrespectfully" 82\%, "Enjoy making other people feel better" 81,40\%, "Have tender, concerned feelings for people less fortunate than him/her" $77 \%$, "Can tell when others are sad even when they do not say anything" $77,80 \%$, "Get a strong urge to help when seeing someone who is upset" $81,60 \%$ and "When seeing someone being taken advantage of, feel kind of protective towards him/her" $80,20 \%$. The standard deviation of the mean values for each statement is 0,11 . Further discussion for the lower ratings of this section is following in the discussion section

\subsection{Limitations of this research}

It is a duty for every researcher to recognize the limits of his / her research towards the topic ever selected. Regarding this exploratory research, the sample of 100 participants used may not be adequate enough to generalize the results on the public accurately. But as the results were mostly awaited to have this form, meaning some leadership characteristics having a higher level of agreeability and others lower, the validity of them may be enough for certain occasions.

The sample used in this research may be addressed at least on a $70 \%$ as a probability sample was used to that extent with the questionnaire being sent via emails or social media to friends and acquaintances of the research. But as Saunders et al. propose, "the data collected using a survey strategy is unlikely to be as wide ranging as those collected by other research strategies. For example, there is a limit to the number of questions that any questionnaire can contain if the goodwill of the respondent is not to be presumed on too much. Despite this, perhaps the biggest drawback with using a questionnaire as part of a survey strategy is the capacity to do it badly!" (Saunders et al., 2016, pp. 182). So if by 70\% a probability sample of those who answered the questionnaire in goodwill was used, the rest $30 \%$ may did not completely understand the questions or answered randomly, although the results may prove the hypotheses set for the public.

It is also worth noting that, wider use of academic journal articles and researches may mean for some that a research has greater validity or that more relevant resources are used. This should also be recognized as a fact taken into consideration as a limitation for this research, in combination of course with the solely descriptive statistic methods used in the analysis.

\section{Discussion and Recommendations}

\subsection{Proposals for change of culture and resilience - "The visionary boss"}


Some may say that there is a contradiction between the terms "vision" and "boss", as boss is something bad for some, right? Leader is the "good word", but unfortunately this is not for everyone but solely for those who understand the difference between a leader and a boss. As it has been mentioned above, "the real leader is the one who has no need to lead, he is content to point the way" (Henry Miller). But as some parts of the public percept a boss as their leader, for this profile is about "the visionary boss".

A "visionary boss" may be a term referring to people who are in charge of their business, with visions and dreams for its development, while at the same time their employees perceive them as bosses and not as leaders. In many cases in business reality, there have been "visionary bosses", being those who although they had a vision and they tried to communicate it, to implement it and to thrive their businesses through it, failed to change the culture of their employees and failed not only to fulfill their dreams but even lost their business. People see them as "bosses" when in the mean time they have prominent leader characteristics. Although being humane, they are treated like being relentless money pursuers. Many might have been authoritarian in cases, many might have been communicative and appealing but in fact they were, most of the times at least, dealing with the " $X$ " people. Douglas McGregor in his " $X$ " and "Y" theory, divided the people between those who can and those who " refuse to work" being the "X" $X$ and those "cheering the opportunity to work" being the "Y""s (McGregor, 1960). The ' $X$ ' people is in fact those who may not only simply refuse to work, but also refuse to follow orders and disregards a leader as intuitionally they regard them as "the bad bosses giving them orders and abusing them while they know less than them" (McGregor, 1960). People like them may have an utterly negative mood towards their job and their reality. McGregor might have been totally pessimistic about these employees as he believed "they cannot change" (McGregor, 1960) and that there are two different types of management to be followed for each case, either "X" or "Y". But what if they could change, as Schein later proposed with theory "Z"? (Maslow, 1969)

In some cases there is a possibility for people who may seem rather incompetent for the position at first, to be able to perform well if the motivation needed is given. And as the recruitment of "Y" people is not always an easy and fast task, the adoption of parts of the "Z" theory of Maslow may be the solution a "visionary boss" shall follow to see his/ her visions fulfilled efficiently (Maslow, 1969). With a corresponding analysis of the " $Z$ " theory, it may be proposed that a wise yet "visionary boss", carries out a strategic planning in which physiological needs, safety needs, belongingness and love needs, as well as esteem needs and the need of self - actualization of the employees are approached (Maslow, 1969). Of course this is a long - way process to be followed and a great challenge to be accomplished quickly, but if the managers in a business are trained to adopt a culture towards such a great change, while obviously having general leadership skills, transformations skills and some $\mathrm{m}-\mathrm{s}-\mathrm{c}$ leadership traits, a cultural change that may be performed regardless how many employees are "X" or "Y"'s (McGregor, 1960). And thus, the "visionary boss" shall be able to see his / her visions becoming reality.

\subsection{Proposals for change of culture and resilience - "The continuously unsatisfied employee"}

And now on the other side, there are the "continuously unsatisfied employees", who mainly accuse the employers in overall for their situation, like if the whole world is turning around them or they are the target of all the disasters. Of course, tremendous sacrifices have been made 
for the labor rights movement, since the era of "Taylorism" was gradually abolished, but in overall for more than 30 years there is a perception that only the labor class is the of "the righteous men" and the rest is "the evil men". But yet of course, this is not a perception regarding employees as a whole, but only those that shall be addressed with the term "the continuously unsatisfied employee".

This kind of employees is indicative of a lazy yet incompetent employee who believes he / she is able and has the knowledge to get his / her job done. people mainly seek for ways to loaf around, while in the same time demanding pay rises they think they disserve. In fact, these people are an ordinary " $X$ " type, based on McGregor's theory (McGregor, 1960), that cannot withstand pressure, resist to changes and may have no sense of survival during a crisis. It is maybe because the younger generations were raised without the shortages their parents may have who may also have spoiled them or give them a wrong perception about work and life. Because of the shortages their parents may have survived, they may have raised their children without learning them about money - saving, or because they had passed through economic deficiency and harshness themselves they may simply want to make money with few if any working. It may be indeed a matter of lesser or false education, or maybe the education system has failed in total. But yet there shall be no intention proposing that all employers are righteous and employees are the evil, and without any other denouncement about this kind of employees what could be done for those people, who are yet definitely working for their needs? Is it because they have not understood their real needs?

An attainable solution for a conversion of the "continuously unsatisfied employees" to "happy and productive employees" is, as it has been analyzed above, a task closely related with contemporary leadership theories. As a whole concept it may be described with one word, motivation. This might be meaning that the "visionary boss", as analyzed above, shall implement for this conversion a specialized form of the " $Z$ " theory of motivation (Maslow, 1969), in order to revert these people's attitude towards their job and thus create more profit through their performance for the organization combined with senses of faith, honor and dignity. Their physiological, safety, belongingness, love, esteem and self - actualization needs may be fulfilled to an extent that they turn from unsatisfied and unproductive to satisfied and productive. But yet again many would argue that a business should be selecting the suitable people for the suitable positions and that anyone who cannot survive the competition should be left out, so why should any business try to change these people? Because in fact it may be proposed that each and every employee has both the " $\mathrm{X}$ " and the " $\mathrm{Y}$ " side, the one less augmented than the other maybe, and so with a visionary modern strategy prepared, there will be more "Y"'s and less "X"s.

The overall engagement of the staff shall be more intense if there is motivation and a persistent strategy to lean on, which may gradually become a culture and make the organization ready to withstand any outer or inner pressure, thus remaining resilient. But it should be noted at last that those who don't fit a working environment, should step down before they damage themselves and the business more. It shall be stated that in fact, people sometimes pursue a better career not simply because of the money but also because of feelings, good or bad. And these feelings shall be expressed properly, so these people do not get suppressed and tore apart. They shall not become extremely alienated from their overall environment, both at job and at home. 


\subsection{Proposals for change of culture and resilience - "The extra rigorous advisor / the once expert student"}

As every novelty demands desperately new ideas and a new, broader perspective, towards a culture change for resilience many experts may come across to advise the "visionary boss" in implementing his/ her new plans. These may be called the "extra rigorous advisors" who once where "'expert' students, literally or figuratively. But yet this choice of those fitting for this job may not be a simple case of recruitment, as the impact of this decision is affecting the plans of a whole organization. These "extra rigorous advisors" may be experts of the human resources management, recruiters, business magnates or life and career coaches. But as many professionals have been so far related in coaching and business consulting, there are many who would argue if these people might indeed provide solutions that are working and bringing high performance, and not simply make more money for themselves.

The doubts arisen are based on the fact that there are more coaches and consultants than may be ever needed. When only in a single union of coaches in Europe there are over 5000 members (hca.com.gr, 2020), this means that some may be simply pursuing a career in coaching and consulting because of the market share of the segment. Yet of course there is a vast amount of consultants, recruiters and business magnates who are selling their advices pretty well and who have been proven through their work they worth it, for bringing performing results for a business. So the choice of an "extra rigorous advisor" may be a game - changing event, a turning point for a business when it comes to implementing a big change for future resilience.

But when a business or an organization comes across a period in which an expert is needed to provide solutions that shall be a preparation for a cultural change and resilience, deep and thorough examination of the whole organizational scheme shall be made. It would be proven helpful for a "visionary boss" to remember when choosing for a consultants team that these are the people who shall propose manners for a change, for resilience, for risk management, for corporate governance, financing etc. but they are not those who implement the change, they simply facilitate it to happen. As it has been analyzed and researched through the section of the survey referring to transformational leadership, even leaders are not those who mainly implement a change. A leader's "job" is to aspire the employees in order to implement a transformation, a matter of culture based on Schein's definition (Schein, 1985), to make them develop solutions themselves and take responsibility for their actions that may improve the organization, and thus their everyday life and so on. So a great "extra rigorous advisor" shall propose the solutions towards a new culture and a resilient future, but the "visionary boss" the leader- is the one who shall make this understood to the employees of an organization, as they are the "executers". The relevant leadership literature with ample evidence and theories, as the efficiency vs effectiveness approach used by Chris Argyris, shall be also a cornerstone for a fine choice of a principled and well - disciplined "extra rigorous advisor", as the use of proven models proposed in literature that might be taken for granted when judging the validity of a choice of advisor.

\section{Conclusion}

On the times that "they are a - changing" as Bob Dylan sang more than 50 years ago, organizations an institutions are challenged on a close call both by their environment and most importantly by their people, meaning their employees. Leadership for a hard future shall be the main stance for a leader to be prepared, especially when on a hard future job performance shall 
be maintained at the highest-level possible (Hougaard and Carter, 2018). But when job performance even when it is up - kept high is simply present opportunely without any deep sense of duty and personal satisfaction, the game unfortunately may get lost. Without a sensible yet bright vision from a leader, and especially without this being communicated vividly throughout an organization as a whole, the chances of survival of the organization are rather sparse and the competitive advantage rather hidden and disappeared (Porter, 1985). So a visionary leader has to be prepared for a brave new world, when it comes to resilience and change implementation, especially regarding culture. Accuracy of actions and strength of character may be evidently needed.

The survey conducted for this research in fact proved the overall anti-modern approach of the public regarding leadership and job performance. Three of the four hypotheses set initially were more or less proven and one was wrong at all. Gender, age and monthly allowance does not affect the perception one has towards the leadership skills that influence high job performance (Hypothesis 1), as the level of agreeability with the rest of the questions in the other sections was high $(4,25$ out of 5$)$ regardless of age, gender and monthly allowance, and thus this proved at last that demographics had no implication in this study. Moreover, the General Leadership Skills have in overall a high level of approval among the public (Hypothesis 2) but the specific traits referred in the hypothesis were not all on a high approval rating. Except of trustworthiness (rated $3^{\text {rd }}$ out of 14 traits), articulateness ( $7^{\text {th }}$ out of 14 traits), dependability ( $9^{\text {th }}$ out of 14 traits), friendliness ( $11^{\text {th }}$ out of 14 traits), empathy (12 out of 14 traits) and outgoingness $\left(13^{\text {th }}\right.$ out of 14 traits) received lower ratings, and this may mean this hypothesis was proven just in overall. Transformational Leadership skills also have a relatively high level of acceptance between the public regarding job performance development even on an inner cultural change basis, but the implementation of a change received lower level of agreeability for a leader, meaning that the public supposes that employees shall implement a change and not employers / leaders (Hypothesis 3), so this hypothesis was partially proven. On the other side, Modern Leadership Theories have moderate to low level of acceptance among the public (Hypothesis 4), regardless their academically acknowledged influence in job performance, thus proving this hypothesis in total.

The solutions discussed for this "anti - modern" culture to change through three different profiles of people, being the "visionary boss", the "continuously unsatisfied employee" and the "extra rigorous advisor", are simply some sparse possible recommendations that may be adopted in each case in order to promote a change culture for a resilient future to come. Constant changes are the challenge a leader, a "visionary boss", should always face, but the values on which he / she lays on shall not change to anything worse. Through this long - way to the top, feelings may become overwhelming, crushing the whole good attitude he/ she may have in facing a new situation, while common sense may sometimes remain deprived away. But when pursuing for something good in businesses and organizations, the fulfillment of the needs of those living in, through and out of it shall be on the center of thought. And as no one is full, a try for those who are "less full" may really worth it.

\section{Acknowledgment}

This paper is dedicated to Christina. This paper is part of the thesis submitted for the MBA studies completion at Derby University (Mediterranean College campus Greece). 


\section{World Conference on MANAGEMENT, BUSINESS and ECONOMICS}

26-29 March, 2021

\section{References}

Barnard, C. (1948). Organization and Management Selected Papers, London, UK: Routledge.

Bass, B.M. and Stogdill, R.M. (1990). Bass \& Stogdill's Handbook of Leadership: Theory, Research, and Managerial Applications, New York, NY, USA: Simon and Schuster.

Brown, D. (2020), Mark Cuban on Why You Should Start a Business Now, https://www.inc.com/damon-brown/mark-cuban-on-why-you-should-start-a-businessnow.html, accesed on 25/07/2020.

Bryman A. and Bell E. (2015). Business Research Methods, 4th edn. Oxford: Oxford University Press.

Chemers, M. (1997). An integrative theory of leadership, London, UK: Routledge.

Follett, M.P. (1918). New State: Group Organization, University Park, PA, USA: The Pennsylvania State University Press.

Goleman, D. (2000). "Leadership that gets results", Harvard Business Review, vol78, no2, pp. 78-90, Boston, MA, USA: Harvard Business Review Publishing Corporation.

Heifetz, R.A. and Laurie, D.L. (2002). "The Work of Leadership", Best of Harvard Business Review, Boston, MA, USA: Harvard Business Review Publishing Corporation.

http://www.hca.com.gr/en/

Hougaard, R. and Carter, J. (2018). The Mind of the Leader: How to Lead Yourself, Your People, and Your Organization for Extraordinary Results, Boston, MA, US, Harvard Business Review Press.

Jacobs, T. O., and Jaques, E. (1990). Military executive leadership. In K. E. Clark \& M. B. Clark (Eds.), Measures of leadership (p. 281-295), Leadership Library of America.

Lewin, K., Lippitt, R., and White, R. K. (1939). Patterns of aggressive behavior in experimentally created "social climates." The Journal of Social Psychology, vol10, no1, pp. 271-299, London, UK: Routledge.

Maslow, A. H. (1969). “Theory Z”, Journal of Transpersonal Psychology, vol1, no2, pp. 31-47, New York, NY, US: Viking.

McGregor, D. (1960). The human side of enterprise, New York, NY, US: McGraw Hill Book Co.

Northouse, P. (1997). Leadership: Theory and Practice, Los Angeles, CA, US, SAGE Publications.

Porter, M.E. (1985). Competitive Advantage, New York, NY, USA: Free Press.

Rooke, D. and Torbert, W. R. (2005). Seven Transformations of Leadership, Harvard Business Review, April 2005, Boston, MA, USA: Harvard Business Review Press.

Saunders, M. K, Lewis, P. and Thornhill, A. (2016). Research Methods for Business Students, 7th edn. Harlow, UK: Pearson.

Schein, E.H. (1985). Organizational Leadership and Culture, Hoboken, NJ, US, John Wiley and Sons Inc. 


\section{World Conference on MANAGEMENT, BUSINESS and ECONOMICS}

26-29 March, 2021

Scheidel, W. (2017). The great leveler: violence and the history of inequality from thestone age to the twenty-first century, Princeton, NJ, US: Princeton University Press.

Spreng, R.N., McKinnon, M.C., Mar, R.A. and Levine, B. (2009). "The Toronto Empathy Questionnaire: Scale Development and Initial Validation of a Factor-Analytic Solution to Multiple Empathy Measures", Journal of Personality Assessment vo191, no1, pp. 62-71, Oxfordshire, UK, Routledge, Taylor and Francis Group LLC.

Thom, R. (1989). Structural Stability and Morphogenesis, Boulder, CO, US: Westview.

Warrick, D.D. (2011). The Urgent Need for Skilled Transformational Leaders: Integrating Transformational Leadership and Organization Development, Journal of Leadership, Accountability and Ethics 8(5), Atlanta, GA, US, North American Business Press, Inc.

Zikmund, W.G, Babin, B.J., Carr, J.C. and Griffin, M. (2010). Business Research Methods $8^{\text {th }}$ edition, Boston, MA, USA: South Western Cengage Learning. 